\title{
THE ELECTROCARDIOGRAM IN THE DIAGNOSIS OF SYSTEMIC HYPERTENSION
}

\author{
BY \\ WILLIAM EVANS \\ From the Cardiac Department of the London Hospital \\ Received February 22, 1962
}

A diagnosis of systemic hypertension depending solely on a reading of the arterial blood pressure has the imprint of archaism upon it, for very high readings are frequently obtained in healthy subjects. A persistence in this clinical habit misleads diagnosis and introduces an unwarranted handicap into the lives of countless individuals. This imposed handicap includes rejection for life assurance or the burden of an increased premium in the event of acceptance, denial of employment when this is conditional on a satisfactory medical examination, failure to enter a superannuation scheme, and actual invalidism in nervous subjects, or in any who may be subjected to prolonged treatment with the potent hypotensive drugs of the day.

The need, therefore, is to place the diagnosis of systemic hypertension, a disease of considerable virulence, on a secure basis, and to distinguish from it the innocent state of hypertonia (Evans, 1957) in which a clinical examination might discover the blood pressure to be raised at times to impressive heights. The purpose of this work has been to contribute to the fulfilment of this need.

In all, 520 cases were specially examined, and they were assembled consecutively until an adequate number was included in the respective groups intended for study. Thus, there were 50 healthy children and young adults, 100 healthy older adults, 100 patients with cardiac infarction in whom the blood pressure was regarded as normal, 70 healthy subjects with hypertonia, 100 patients with systemic hypertension, and 100 patients with hypertension where cardiac infarction or heart failure had been added as a complication.

The criteria that qualified the admission of patients into their respective groups will be described more fully when these are considered separately. Clinical examination sought the pathological changes identified with systemic hypertension, when the presence of contracted arterioarteriolar vessels was of special significance. Thus, an estimate was made of the degree of firmness and narrowing (contracture) of the brachial arteries, as well as the bore of the retinal arterioles, calculated from their pallor which served as an index of the volume of the blood stream and of the diameter of the lumen. The outline of the heart was determined by radiological examination, which also disclosed the state of the lung fields. Finally, an electrocardiogram was taken in search of the earliest evidence of left ventricular hypertrophy.

The electrocardiogram in all cases was recorded by the Sanborn Viso Cardiette, standardization of the tracing being effected by arranging for a deflection of one centimetre in the recording arm when a current of one millivolt was introduced into the circuit. The bipolar CR leads were chosen deliberately in preference to $\mathrm{V}$ leads because a competent record was needed from station 7 in the posterior axillary line, a position towards which the left ventricle reaches in the course of its progressive enlargement, and where a record from a V lead arrangement is unsatisfactory. Symons and Wahl (1961) met with this disadvantage for they stated that the classical cardiographic changes of left ventricular hypertrophy may be difficult to recognize in the greatly enlarged or transverse heart, 
in that the tracing obtained at V5 or V6 in these patients did not record the maximum electrical events due to the left ventricle because the transitional zone was displaced to the left.

Although it has long been recognized that depression of the T wave and S-T segment is a characteristic feature of the electrocardiogram of patients with left ventricular enlargement from hypertension (Rykert and Hepburn, 1935), the same deformity in the tracing follows cardiac infarction when the injury is laterally and postero-inferiorly disposed. The need is to discover signs that are not wholly obscured by superimposed cardiac infarction and that can tell of early hypertrophy of the left ventricle. This task was not expected to be easy for Wilson et al. (1944) stated that it was impossible to diagnose the lesser grades of left ventricular hypertrophy with any degree of certainty. Selzer $e$ t al. (1958a) also warned that criteria advanced for the recognition of such early enlargement, should be applied with an understanding of their limitations, and urged their acceptance as an expression of the probability, rather than certainty, that they can tell the size of the heart.

Before the advent of chest leads it was known that left ventricular hypertrophy gave rise to a tall $R$ wave in lead I and a deep S wave in lead III, and later when the indifferent electrode was placed to the right of the transitional zone the $S$ wave was found to be deep, while to the left of this zone the $R$ wave became tall. Translated into electrocardiographic terms, therefore, an increase in the voltage of the left ventricular deflection consequent on left ventricular hypertrophy, shows itself as a tall $R$ in lead I, a deep $S$ in the right pectoral lead CR1, a large RS deflection in the apical lead CR4, and a tall $\mathrm{R}$ in the posterior axillary lead CR7; depending on the relationship of the CR4 electrode to the transitional zone the ventricular deflection may reflect a preponderance of the left ventricle in either $\mathbf{R}$ or $\mathbf{S}$ waves in this lead.

The next need was to discover minimal values for the amplitude of such waves in these separate leads, which would not be exceeded in the case of healthy subjects and would be found only in those in whom the presence of left ventricular hypertrophy was known with certainty. In the past, discordancy in regard to these values, especially when they have been applied to subjects with a raised blood pressure, in whom for that reason early left ventricular hypertrophy has been presumed present, has arisen from a failure to separate the two clinical groups of patients, namely those with true systemic hypertension and consequently with left ventricular hypertrophy, and those who show only the physiological state of hypertonia. Moreover, in those with low left ventricular deflection values in the presence of considerable enlargement of the left ventricle, sufficient regard has not been taken of the effects of complications like atrial fibrillation, heart failure, or salient cardiac infarction. For these reasons, the cases selected for this investigation had to be representative of the separate clinical states, and so included healthy subjects both with a normal and with a raised blood pressure, as well as patients in whom systemic hypertension appeared both by itself and in company with heart failure and/or cardiac infarction.

A value was ultimately affixed to the preponderant left ventricular deflection in separate leads $\bigcirc$ that served as a standard measure suitable for testing in the different clinical states. These pro- $\rightarrow$ visional values were: the $R$ wave in the limb lead $I(R I)=15 \mathrm{~mm}$.; the sum of the $R$ and $S \cong$. deflections in CR4 (RS4) $=35 \mathrm{~mm}$.; the R wave in posterior axillary lead CR7 (R7) $=20 \mathrm{~mm}$.; the $\stackrel{N}{\circ}$ sum of RI and RS4=45 mm.; the sum of RS4 and R7=50 mm.; and the sum of RI, RS4, and $N$ $\mathrm{R} 7=55 \mathrm{~mm}$.

The depth of the S wave in the right pectoral lead CR1 (S1), the sum of S1 and RS4, the sum of S1, O RS4, and R7, and the sum of RI, S1, RS4, and R7, were also tested, but were found to be less reliable in that each value included the $S$ deflection in CR1. Three circumstances contributed to its unreliability, namely that the voltage of the $S$ wave at this fixed anatomical situation, in the 4th intercostal space at the right sternal $\stackrel{\infty}{\rightarrow}$ border, varies in relation to the height of the diaphragm with corresponding elevation or depression of the heart to different levels. Moreover, the $S$ wave is annulled should right bundle-branch block be present, or becomes exaggerated if left bundle-branch block is an electrocardiographic feature of hypertension, as it sometimes is.

These provisional values, or ones in excess of them, meaning an unusual excitability of the $\stackrel{\mathbb{D}}{\stackrel{\circ}{\circ}}$ left ventricle, were not expected often, if at all, in the healthy series, while their incidence should be common or invariable in patients with uncomplicated systemic hypertension where changes in the $\mathrm{T}$ 
wave and S-T segment in leads I and CR7 indicate left ventricular preponderance from left ventricular hypertrophy.

When the amplitude of the ventricular deflections in the selected individual and combined leads had been recorded in healthy subjects, the figure that proved to have greatest value was that represented by the sum of RI, RS4, and R7. If this was $55 \mathrm{~mm}$. or greater it was accepted as abnormally high and as evidence of left ventricular excitation.

\section{LEFT VeNTRICULAR EXCITATION}

An increase in the voltage of deflections identified with the left ventricle in hypertension has been attributed by many authors to the approximation of the free wall of the hypertrophied left ventricle to the chest wall, whereby the exploring electrode subtends a much wider angle and in this way records higher potential variations. An additional factor might be a decrease in the volume of the poorly conducting lung between the heart and the chest wall (Lepeschkin, 1951; Barker, 1952; Grant, 1953; Bayley, 1958). These explanations based on anatomical considerations do not, however, satisfy the conditions that frequently prevail in patients with hypertension, namely an increased voltage in the electrocardiogram in the absence of any discernible enlargement of the heart determined by radiological examination. It would appear in such instances, and they are common, that the left ventricle reacts to the added work imposed on it in the case of systemic hypertension by an increased resistance in the peripheral circulation, responding with heightened excitation and increasing its effort and energy. The incidence of this response will now be described for the five clinical groups.

\section{HEALTHY SERIES}

It is known that the ventricular deflections obtained from leads over the left ventricle are greater in the case of young subjects than in adults (Sokolow and Lyon, 1949; Grant, 1957; Ziegler, 1951). When the amplitude of the ventricular deflections for the combined leads was calculated in 50 healthy young subjects between the ages of 11 and 34 years and with a mean age of 21 years, the measure for RI/RS4/R7 exceeded the value of $55 \mathrm{~mm}$., which had been regarded as standard, in eight instances. The mean value for the series was $45 \mathrm{~mm}$. compared with $39 \mathrm{~mm}$. for the group of healthy adults (Table I). This disparity in the amplitude of the ventricular deflection in leads over the left

TABLE I

Mean Values of Preponderant Left Ventricular Deflections

\begin{tabular}{|c|c|c|c|c|c|c|c|c|c|c|c|}
\hline \multirow[b]{2}{*}{ 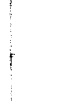 } & \multirow{2}{*}{\multicolumn{3}{|c|}{ Description of cases }} & \multirow{2}{*}{$\begin{array}{c}\text { Mean } \\
\text { age }\end{array}$} & \multirow{2}{*}{$\begin{array}{c}\text { Mean } \\
\text { blood } \\
\text { pressure }\end{array}$} & \multicolumn{6}{|c|}{ Leads and amplitude of ventricular deflections in $\mathrm{mm}$. } \\
\hline & & & & & & $\mathbf{R I}$ & RS4 & R7 & RI/RS4 & RS4/R7 & RI/RS4/R7 \\
\hline \multicolumn{4}{|c|}{ Healthy young subjects.. } & 21 & $135 / 85$ & 5 & 25 & 15 & 30 & 40 & 45 \\
\hline \multicolumn{4}{|c|}{ Healthy adult subjects .. } & 55 & $150 / 90$ & 7 & 21 & 11 & 28 & 32 & 39 \\
\hline \multicolumn{3}{|c|}{ Cardiac infarction series } & . & 56 & $145 / 95$ & 7 & 21 & 11 & 28 & 32 & 39 \\
\hline \multicolumn{2}{|c|}{ Hypertonia } & .. & . & 59 & $220 / 125$ & 8 & 21 & 12 & 29 & 33 & 41 \\
\hline \multicolumn{2}{|c|}{ Hypertension } & .. & $\therefore$ & 57 & $230 / 130$ & 13 & 34 & 20 & 47 & 54 & 67 \\
\hline \multirow{2}{*}{ 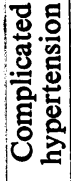 } & \multicolumn{3}{|c|}{ Added cardiac infarction } & 62 & $215 / 125$ & 11 & 31 & 17 & 42 & 48 & 59 \\
\hline & \multicolumn{3}{|c|}{ Added heart failure } & 62 & $215 / 135$ & 10 & 27 & 16 & 37 & 43 & 53 \\
\hline
\end{tabular}

Symbols in this and in subsequent tables have the following meaning. RI: the height of the $\mathbf{R}$ wave in limb lead I. RS4: the sum of $\mathbf{R}$ and $S$ deflections in the apical lead CR4. R7: the height of the $R$ wave in the posterior axillary lead CR7. 
ventricle in young subjects is also evident in Leatham's series (1950) where 50 of his 100 cases be- $\frac{\stackrel{2}{c}}{c}$ longed to a younger age group of 18 to 40 years, and this accounted for the relatively high values he obtained for the R waves, namely greater than $35 \mathrm{~mm}$. in CR4 in 16 cases, and exceeding $20 \mathrm{~mm}$. in $\stackrel{\text { ? }}{?}$ CR7 lead in 4 cases. It is clear, therefore, that a higher standard value in respect of ventricular $\frac{D}{0}$ deflections has to be adopted for young subjects. In that the diagnosis of systemic hypertension has $\frac{\bar{\sigma}}{\bar{\omega}}$ seldom to be entertained in this younger age group, the critical voltage for the ventricular deflections in selected leads was not sought in a larger number, but it is likely that for the RI/RS4/R7 combination this value might be $65 \mathrm{~mm}$. for young subjects instead of $55 \mathrm{~mm}$. in older adults.

The series of healthy adult subjects consisted of 100 cases, 69 men and 31 women. Their. ages were 35 years or older, and the mean age was 55 years. They were admitted into the series $\overrightarrow{\vec{\omega}}$ after clinical examination, including cardioscopy, had found them to be healthy. The blood pressure was always less than $200 / 110$, while the mean value for the group was $150 / 90 \mathrm{~mm}$. of $\mathrm{Hg}$. The somewhat higher limit of normal was adopted deliberately in order to introduce a more severe test $\stackrel{N}{+}$ for the usefulness of the electrocardiogram in the detection of left ventricular hypertrophy based on + the presence of left ventricular excitability, and in order to decide on the amplitude of the ventricular $\overrightarrow{8}$ deflection that might be adopted as the standard measure in health in the case of the adult. Healthyo subjects with similar or higher blood pressure values were regarded as instances of hypertonia, and will be considered under that head.

In 96 of the 100 cases the amplitude of the predominant left ventricular deflections was less than $55 \mathrm{~mm}$. which was the value accepted provisionally as standard for RI/RS4/R7; the mean value for $\vec{\oplus}$ the group was $39 \mathrm{~mm}$. (Table I). In 58 cases this measurement was $40 \mathrm{~mm}$. or less, and was $35 \mathrm{~mm}$. N or under in 38 . In only 4 was the standard value of $55 \mathrm{~mm}$. exceeded, the actual values being 59,60 , ᄋ 64, and $96 \mathrm{~mm}$. respectively (Fig. 1 and Table II).

TABLE II

Left Ventricular Excitation in 4 of 100 Healthy Subjects and in 9 of 100 Patients with Cardiac Infarction and Normal Blood Pressure

\begin{tabular}{|c|c|c|c|c|c|c|c|c|c|c|}
\hline \multirow{2}{*}{ Description of cases } & \multirow{2}{*}{$\begin{array}{l}\text { Case } \\
\text { No. }\end{array}$} & \multirow{2}{*}{ Sex } & \multirow{2}{*}{ Age } & \multirow{2}{*}{$\begin{array}{c}\text { Blood } \\
\text { pressure }\end{array}$} & \multicolumn{6}{|c|}{$\begin{array}{l}\text { Amplitude in mm. of ventricular deflections in } \\
\text { separate or combined leads }\end{array}$} \\
\hline & & & & & RI & RS4 & R7 & RI/RS4 & $\mathbf{R S} 4 / \mathbf{R} 7$ & RI/RS4/R7 \\
\hline Series of healthy subjects & $\begin{array}{l}1 \\
2 \\
3 \\
4\end{array}$ & $\begin{array}{l}\mathbf{F} \\
\mathbf{M} \\
\mathbf{M} \\
\mathbf{M}\end{array}$ & $\begin{array}{l}68 \\
55 \\
51 \\
54\end{array}$ & $\begin{array}{l}190 / 100 \\
190 / 105 \\
135 / 90 \\
170 / 100\end{array}$ & $\begin{array}{r}17 \\
10 \\
5 \\
13\end{array}$ & $\begin{array}{l}30 \\
28 \\
42 \\
50\end{array}$ & $\begin{array}{l}17 \\
22 \\
12 \\
33\end{array}$ & $\begin{array}{l}47 \\
38 \\
47 \\
63\end{array}$ & $\begin{array}{l}47 \\
50 \\
54 \\
83\end{array}$ & $\begin{array}{l}64 \\
60 \\
59 \\
96\end{array}$ \\
\hline Series of cardiac infarction & $\begin{array}{l}1 \\
2 \\
3 \\
4 \\
5 \\
6 \\
7 \\
8 \\
9\end{array}$ & $\begin{array}{l}\mathbf{M} \\
\mathbf{M} \\
\mathbf{M} \\
\mathbf{M} \\
\mathbf{M} \\
\mathbf{M} \\
\mathbf{M} \\
\mathbf{M} \\
\mathbf{M}\end{array}$ & $\begin{array}{l}58 \\
68 \\
62 \\
46 \\
52 \\
60 \\
52 \\
63 \\
35\end{array}$ & $\begin{array}{l}170 / 95 \\
180 / 110 \\
160 / 110 \\
130 / 100 \\
180 / 105 \\
170 / 100 \\
130 / 80 \\
165 / 100 \\
150 / 100\end{array}$ & $\begin{array}{r}10 \\
7 \\
10 \\
15 \\
12 \\
13 \\
7 \\
15 \\
4\end{array}$ & $\begin{array}{l}35 \\
42 \\
33 \\
36 \\
33 \\
35 \\
34 \\
32 \\
31\end{array}$ & $\begin{array}{l}15 \\
11 \\
15 \\
10 \\
15 \\
10 \\
15 \\
16 \\
20\end{array}$ & $\begin{array}{l}45 \\
49 \\
43 \\
51 \\
45 \\
48 \\
41 \\
47 \\
35\end{array}$ & $\begin{array}{l}50 \\
53 \\
48 \\
46 \\
48 \\
45 \\
49 \\
48 \\
51\end{array}$ & $\begin{array}{l}60 \\
60 \\
58 \\
61 \\
60 \\
58 \\
56 \\
63 \\
55\end{array}$ \\
\hline \multicolumn{5}{|c|}{$\begin{array}{l}\text { Mean amplitude of ventricular complexes in both healthy and } \\
\text { cardiac infarction series }\end{array}$} & 7 & 21 & 11 & 28 & 32 & 39 \\
\hline
\end{tabular}

At the time, these 4 cases, although with normal blood pressure readings, were regarded as subjects likely to develop hypertension. On this account their progress was followed; but as yet, $\stackrel{\odot}{\circ}$ during a period of two to seven years, none has developed the condition although their ages are now $57,58,59$, and 76 years. 


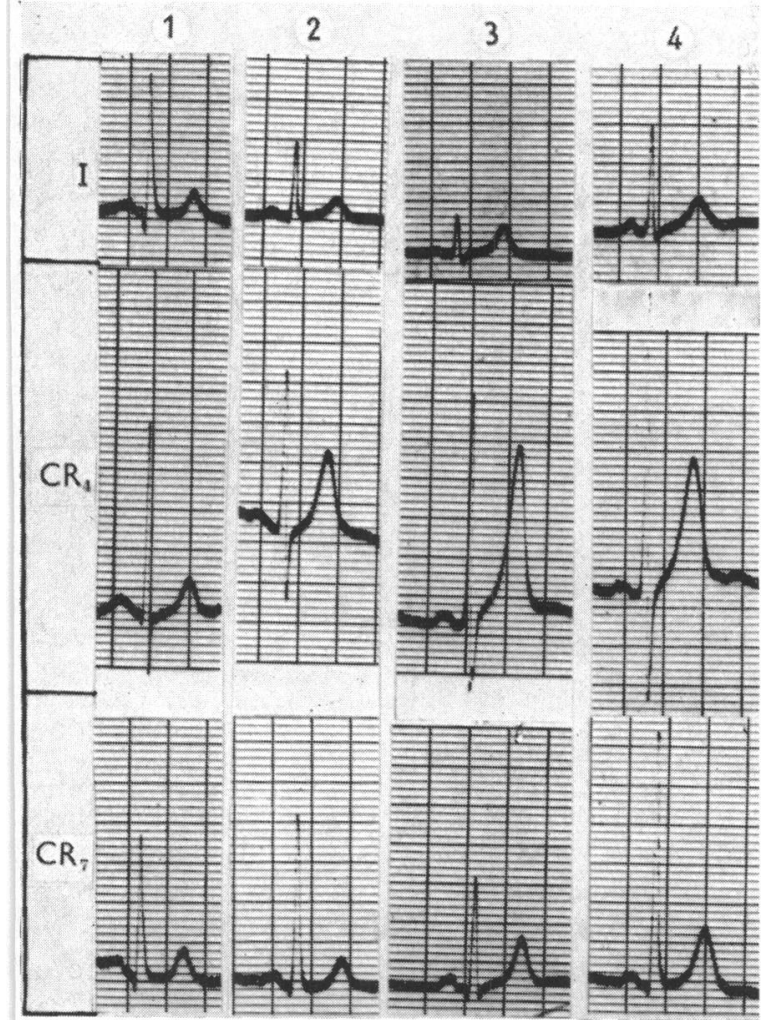

FIG. 1.-Left ventricular excitation in four healthy adults. The amplitude for the lead-combination RI/RS4/R7 was $59,60,64$, and $96 \mathrm{~mm}$. respectively.

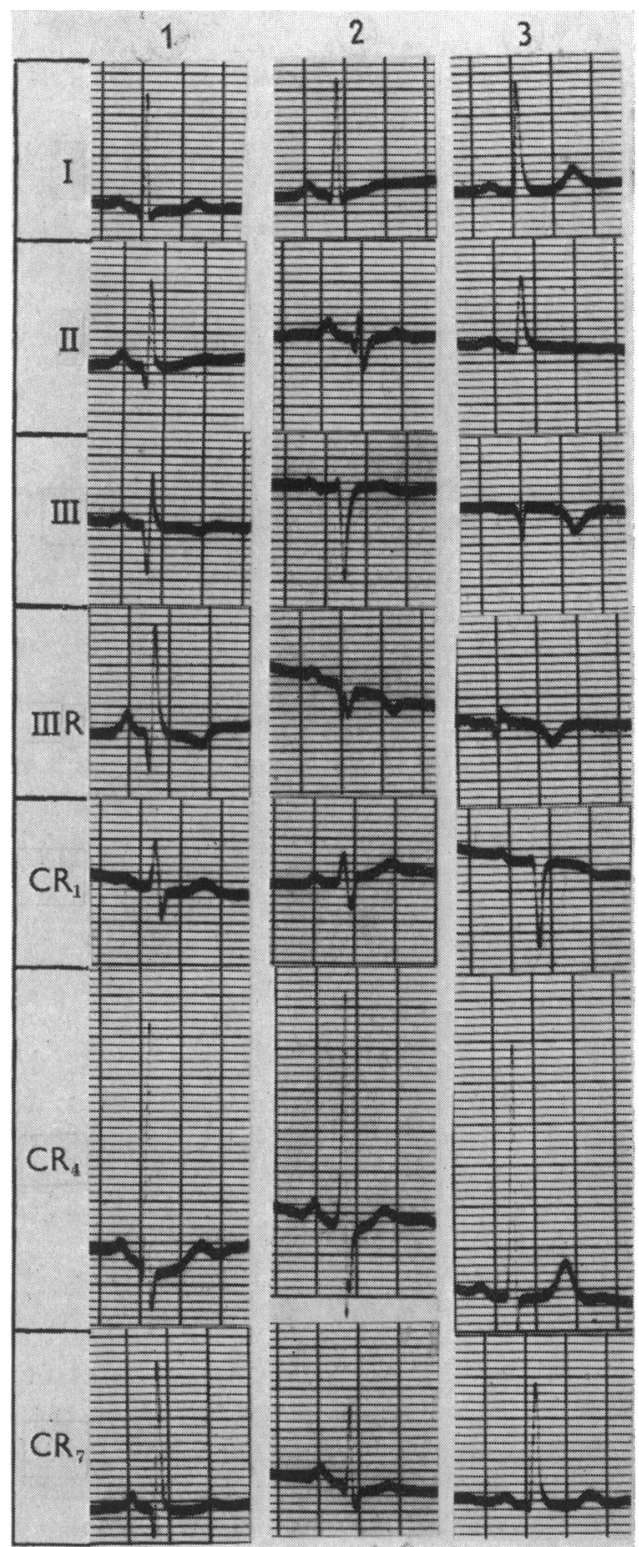

Fig. 2.-Left ventricular excitation in three patients with cardiac infarction disposed laterally and postero-inferiorly, in whom the blood pressure was normal.

Thus, a study of the electrocardiogram in these 100 cases has shown that it is very rare for the tracing to show left ventricular excitability, as instanced by a ventricular deflection amplitude of $55 \mathrm{~mm}$. for RI/RS4/R7, in healthy adults, while in the infrequent exceptions (4 out of 100 in this series) where this value was exceeded, it does not in the absence of $T$ wave and $S-T$ changes in leads $I$ and CR7 presage the development of systemic hypertension. 


\section{CARDIAC INFARCTION}

This group also held 100 cases, 87 men and 13 women. Their ages were 35 years or older, and the mean age was 56 years. The blood pressure was always less than $200 / 110$, and the mean reading for the group was $145 / 95 \mathrm{~mm}$. $\mathrm{Hg}$.

All the patients complained of cardiac pain, and the electrocardiogram in each instance gave proof of the presence of cardiac infarction. In that neither the systolic nor diastolic blood pressures were raised impressively, and that neither heart failure nor substantial cardiac enlargement were present in any member of this group, none was considered to suffer from systemic hypertension where the entry of cardiac infarction had lowered a previously raised blood pressure.

The mean amplitude of the ventricular deflections in the selected leads is shown in Table I, and it will be seen that the values in the separate and combined leads are the same as those found in the series of healthy adults.

In 91 of the 100 patients, the ventricular deflection amplitude was less than the proposed critical measure of $55 \mathrm{~mm}$. for RI/RS4/R7. In only 9 patients was this value reached or exceeded, and they on this account were regarded as demonstrating left ventricular excitation (Table II).

Each of these 9 patients showed changes in the T wave and S-T segment in leads I and CR7 (Fig. 2), but these were considered to have resulted from infarction disposed laterally and posteroinferiorly, and were not the expression of left ventricular hypertrophy identified with hypertension. As in the 4 healthy subjects of the previous group, so also in the case of these 9 patients, having regard to their progress watched over five years, and their ages (seven being over 50 years old), the presence of left ventricular excitation by itself has not been considered as foretelling the ultimate appearance of systemic hypertension.

\section{HYPERTONIA}

Among 70 cases in this group there was a preponderance of the female sex, 49 being women and 21 men. Their ages varied from 38 to 86 and the mean age was 59 years.

In each, the blood pressure was $200 / 110$ or over, and the mean reading for the group was $220 / 115 \mathrm{~mm}$. of $\mathrm{Hg}$. The diastolic pressure was 125 or over in 33 cases. Further clinical examination including cardioscopy failed to discover any other abnormal signs, while their symptoms if present were of the functional kind.

By definition, the electrocardiogram from subjects in this group had to be normal, although during a period of observation, having regard to their ages, it was natural that some of the group fell victims to cardiac infarction from coronary arterial disease. In particular it was conditional for their inclusion in this group that their tracing should not show either left ventricular excitation or depression of the T waves and S-T segment in leads I and CR7 (Fig. 3). The amplitude of the left ventricular deflections was not significantly higher than the corresponding reading obtained from healthy subjects, for the mean value for RI/RS4/R7 was $41 \mathrm{~mm}$. compared with $39 \mathrm{~mm}$. in the control series, which was lower than the standard measure of $55 \mathrm{~mm}$. and much lower than the figure of $\stackrel{N}{\sigma}$ $67 \mathrm{~mm}$. obtained from patients with systemic hypertension where the mean blood pressure was not much higher than in the hypertonia group, namely $230 / 130$ in the former against $220 / 125$ in the latter (Table I).

These results lend emphasis to the importance of the electrocardiogram in the differential diagnosis of this innocent state of hypertonia from systemic hypertension. Symons and Wahl (1961) reporting on their analysis of six parameters of the electrocardiographic diagnosis of left $\stackrel{\mathscr{Q}}{\rightarrow}$ ventricular hypertrophy mentioned that approximately 25 per cent of their 333 cases with a raised blood pressure presented none of the criteria that would support the diagnosis of left ventricular hypertrophy; they considered that such cases represented a benign form of hypertension or hypertonia. The value of an increased voltage of the QRS complex in the diagnosis of left ventricular hypertrophy has been extolled by several writers in the past, and the absence of this cardiographic sign in so many of their cases may be explained by the criteria that they have adopted for the 
diagnosis of hypertension in the cases that they selected for investigation. Thus, in Sokolow and Lyon's (1949) series, 90 per cent of their patients with a blood pressure exceeding $155 / 95$ and a mean value of $197 / 117$ were regarded as having hypertension, while 21 of the 72 cases reported on by Grubschmidt and Sokolow (1957) were said to have hypertensive vascular disease, established from finding blood pressure values exceeding 140/90 and with a mean pressure of $180 / 102$ for the series. Again, Bristow et al. (1961), conducting spatial vectorcardiography in 46 cases of left ventricular hypertrophy included 13 patients in whom systemic hypertension was diagnosed from finding a diastolic pressure of over 100 on most of their visits to the outpatient clinic or hospital during a period of over a year. In these three investigations the acceptance of patients with such relatively low blood pressure values must have meant the inclusion in each of the study-groups of instances of hypertonia in whom the voltage of the ventricular deflections was not expected to be raised, a finding illustrated by the 70 cases described here, in which the blood pressure was sometimes raised to impressive heights and in each case to over $200 / 110 \mathrm{~mm}$. of Hg.

\section{UNCOMPLiCATED SYSTEMIC HyPERTENSION}

This group consisted of 100 patients, 65 of whom were men and 35 women. Their ages varied from 35 to 82 and the mean age was 57 years. Patients with hypertension secondary to coarctation of the aorta, endocrine disease, toxæmia of pregnancy, pyelonephritis, or unilateral renal disease

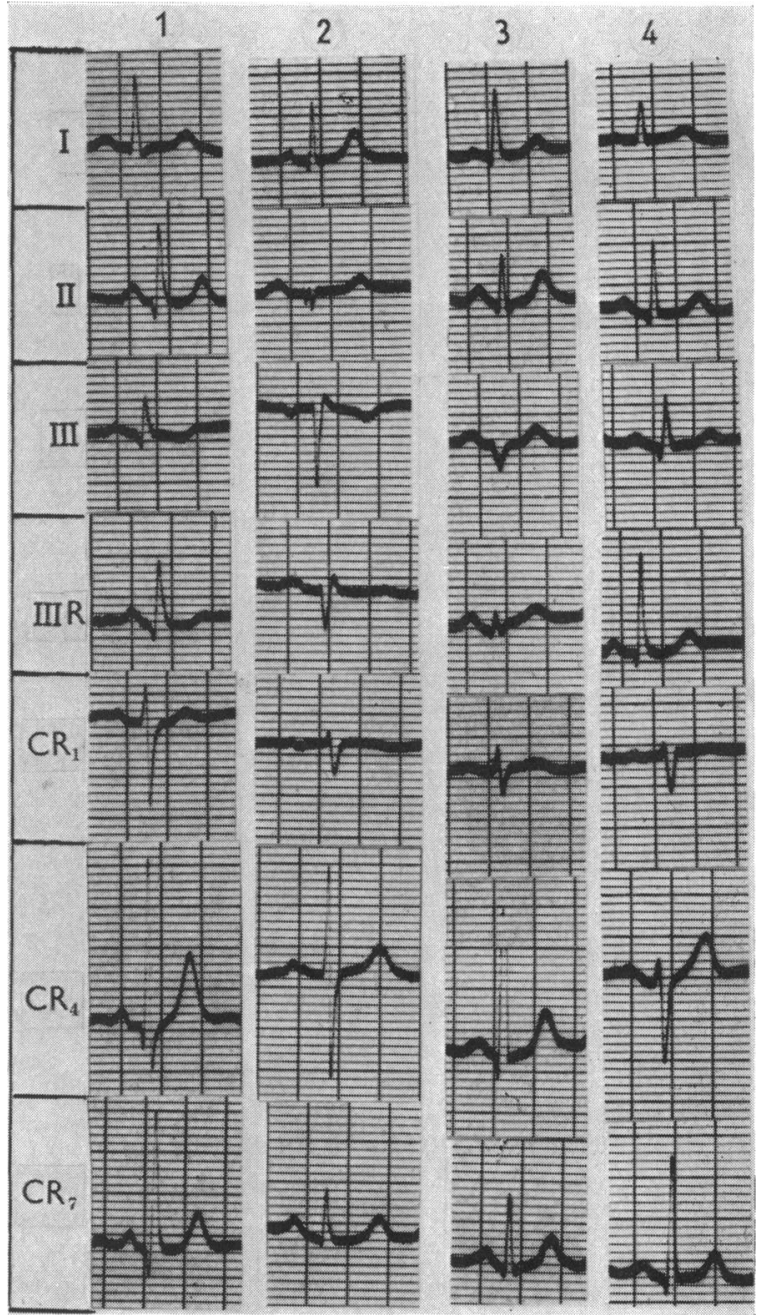

Fig. 3.-Absence of left ventricular excitation in four subjects with hypertonia whose blood pressure was $240 / 120,270 / 145,240 / 150$, and $240 / 130 \mathrm{~mm}$. of $\mathrm{Hg}$ respectively. were excluded from the group, as also were patients with cardiac pain or heart failure.

The diastolic blood pressure was always $110 \mathrm{~mm}$. $\mathrm{Hg}$ or over, and with few exceptions the systolic was over 200 , the mean pressure being $230 / 130 \mathrm{~mm}$. Apart from a raised blood pressure, their acceptance into the group also depended on their electrocardiogram showing a varying degree of depression of the T wave and S-T segment in leads I and CR7, in the absence of digitalization.

The brachial arteries were contracted in 60 cases when they could be described as whipcord; in the remaining 40 they appeared firm to the palpating finger, but they were not narrow. The retinal arterioles were narrow in $\mathbf{5 5}$ instances, but not necessarily in the same cases that showed changes in the brachial arteries, although they appeared side by side in 38 .

At cardioscopy the left ventricle was greatly enlarged in 4, moderately enlarged in 21 , slightly enlarged in 16, and was of normal size in 59 patients.

Left ventricular excitation was present in every case, and the mean amplitude of the ventricular 
deflections in the different leads is shown in Table I. The mean value of $67 \mathrm{~mm}$. for the combination $\mathrm{RI} / \mathrm{RS} 4 / \mathrm{R} 7$ is higher than the proposed standard of $55 \mathrm{~mm}$. and much higher than $39 \mathrm{~mm}$. obtained from the series of healthy adults. As will be seen from Table III the $\mathrm{R}$ wave in lead I contributed least to this high value and the combination RS4/R7, most.

TABLE III

Incidence of Left Ventricular Excitation in Separate Leads in 100 Patients with Systemic Hypertension

\begin{tabular}{|c|c|c|c|c|c|c|}
\hline Ventricular deflections and leads & $\mathbf{R I}$ & RS4 & R7 & RI/RS4 & RS4/R7 & RI/RS4/R7 \\
\hline $\begin{array}{l}\text { Amplitude in mm. initially proposed for the ventri- } \\
\text { cular deflections in the different leads in health }\end{array}$ & 15 & 35 & 20 & 45 & 50 & 55 \\
\hline $\begin{array}{l}\text { Numbers of patients in whom the proposed } \\
\text { amplitude for the ventricular deflections were } \\
\text { reached or exceeded } \ldots \\
.\end{array}$ & 46 & 56 & 61 & 70 & 77 & 100 \\
\hline $\begin{array}{c}\text { Mean amplitude of ventricular deflections for the } \\
\text { series } \ldots\end{array}$ & 13 & 34 & 20 & 47 & 54 & 67 \\
\hline
\end{tabular}

Simpson (1960), reporting on the incidence of a high QRS voltage, depression of the S-T segment, and $\mathrm{T}$ wave diphasia and inversion, in 203 patients with hypertension in whom the diastolic blood pressure at rest in bed exceeded $100 \mathrm{~mm}$. $\mathrm{Hg}$, stated that the incidence of each type of electrocardiographic abnormality increased with the rise in the diastolic blood pressure. In the present series when the incidence of left ventricular excitation was sought in five different grades of diastolic pressure, it was not much commoner in those with a high diastolic reading, for although this tendency was reflected in the group as a whole it could not be applied to individual patients. Thus, left ventricular excitation was low in one with a diastolic blood pressure of $160 \mathrm{~mm}$. of $\mathrm{Hg}$, and high in another with a diastolic pressure of 125 . Moreover, this association was absent in the hypertonia group (Table IV).

According to the extent of the changes in the T wave and the S-T segment in leads I and CR7, the patients were divided into two classes, 62 where such abnormalities were prominent and 38 where they were slight. In the first group the changes were greater in lead I than in CR7 in 5, equal in 6, and greater in CR7 than in I in 51 (Fig. 4). In the second group, showing slight abnormalities, the $T$ was low in lead I with some degree of S-T depression in CR7 in 31 patients; the changes were slight and equal in the two leads in 6 , and in only one patient was the $T$ wave in lead I normal with small changes in CR7 (Fig. 5). The progress of patients exhibiting these minor abnormalies was watched, and in the course of some two years these cardiographic deformities had become exaggerated (Fig. 6); naturally, it was not possible to judge how long the raised blood pressure and the early cardiographic signs had existed side by side, but it seems likely that they appeared together.

The next quest was to discover whether these alterations in the T wave and S-T segment, cardiographic signs identified with left ventricular hypertrophy, were ever preceded by a high amplitude of the ventricular deflections in certain leads as an expression of left ventricular excitation. Mention has already been made of 4 subjects among the 100 healthy adults who showed left ventricular excitation in the absence of abnormalities in the $T$ wave and $S-T$ segment in leads $I$ and CR7, and were watched over periods of two to seven years without either fresh changes in the electrocardiogram or a rise in the blood pressure taking place. Thus, when the several clinical groups were being assembled, and their progress subsequently watched, no single example was found in which a subject with a normal blood pressure and with left ventricular excitation subsequently developed hypertension, nor was there found a patient with uncomplicated hypertension in whom left ventricular excitation was a lone cardiographic sign, for it was always accompanied by ST-T changes. This experience does not tally with that of Scott (1960) who stated that the presence of this high voltage 
TABLE IV

Mean Value of Preponderant Left Ventricular Deflections in 100 Patients with Systemic Hypertension (H) AND 70 Healthy SUbJects With Hypertonia (h)

\begin{tabular}{|c|c|c|c|c|c|c|c|c|}
\hline \multicolumn{3}{|c|}{ Ventricular deflection and lead } & $\mathbf{R I}$ & RS4 & R7 & RI/RS4 & RS4/R7 & RI/RS4/R7 \\
\hline \multicolumn{3}{|c|}{$\begin{array}{c}\text { Mean amplitude of ventricular deflection in healthy } \\
\text { series } \\
.\end{array}$} & 7 & 21 & 11 & 28 & 32 & 39 \\
\hline \multirow{10}{*}{$\begin{array}{l}\text { Mean value of ventricular deflections } \\
\text { in relation to } 5 \text { grades of diastolic } \\
\text { blood pressure shown in } \mathrm{mm} . \mathrm{Hg}\end{array}$} & \multirow{2}{*}{$110^{*}$} & $\mathbf{H}$ & 12 & 34 & 20 & 46 & 54 & 66 \\
\hline & & h & 8 & 20 & 13 & 28 & 33 & 41 \\
\hline & \multirow{2}{*}{$\begin{array}{l}115 \\
\text { or } \\
120\end{array}$} & $\mathbf{H}$ & 14 & 34 & 20 & 48 & 54 & 68 \\
\hline & & $\mathbf{h}$ & 8 & 22 & 12 & 30 & 34 & 42 \\
\hline & \multirow{2}{*}{$\begin{array}{l}125 \\
\text { or } \\
130\end{array}$} & $\mathbf{H}$ & 15 & 32 & 21 & 47 & 53 & 68 \\
\hline & & $\mathbf{h}$ & 8 & 21 & 12 & 29 & 33 & 41 \\
\hline & \multirow{2}{*}{$\begin{array}{l}135 \\
\text { or } \\
140\end{array}$} & $\mathbf{H}$ & 12 & 37 & 20 & 49 & 57 & 69 \\
\hline & & h & 7 & 23 & 11 & 30 & 34 & 41 \\
\hline & \multirow{2}{*}{$\begin{array}{l}145 \\
\text { or } \\
\text { over }\end{array}$} & $\mathbf{H}$ & 15 & 35 & 21 & 50 & 56 & 71 \\
\hline & & $\mathrm{h}$ & 9 & 22 & 12 & 31 & 34 & 43 \\
\hline \multirow{2}{*}{\multicolumn{2}{|c|}{$\begin{array}{l}\text { Mean value of ventricularideflection for both } \\
\text { groups with all degrees of diastolic hyper- } \\
\text { tension }\end{array}$}} & $\mathbf{H}$ & 13 & 34 & 20 & 47 & 54 & 67 \\
\hline & & $\mathbf{h}$ & 8 & 21 & 12 & 29 & 33 & 41 \\
\hline
\end{tabular}

* 110 or under in the case of systemic hypertension.

helps materially in the electrocardiographic diagnosis of left ventricular hypertrophy before typical ST-T changes develop.

The Mechanism of the ST-T Changes. This deformity in the electrocardiogram, related to the early onset of repolarization in the subendocardial region before activation has reached the epicardial surface, has been attributed to myocardial ischæmia or coronary inefficiency by Barker (1952), Winsor and Beckner (1955), and Bayley (1958). Leishman (1951) stated that, having regard to partial correction of the changes by trinitrin ingestion and following sympathectomy, these changes were an expression of cardiac muscle ischæmia determined both by the size of individual muscle fibres and by the inefficiency of the coronary circulation. Harrison and Wood (1949), following injection of the coronary arteries at necropsy in cases with varying degrees of enlargement of the heart from hypertension, found that the size of the coronary arteries increased proportionately to the size of the heart, and they discovered no evidence of relative ischæmia of the muscle of the ventricle in such cases. Cabrera et al. (1952 and 1960) postulated that the diastolic overload of the left ventricle as in mitral or aortic regurgitation had a different effect on the cardiogram from that produced by systolic overload in the case of hypertension and aortic stenosis, but neither Selzer et al. (1958b) nor Sedziwy and Shillingford (1961) could find any material difference between the two electrocardiographic patterns.

Whatever the precise mechanism of these changes may be, and the experience of their correction through inhalation of amyl nitrite or the ingestion of trinitrin (Evans and Hoyle, 1933; Stokes, 1946) appears to propound for them an ischæmic basis, they form an electrocardiographic sign that is inseparable from the diagnosis of left ventricular hypertrophy in systemic hypertension, even at its very inception. Occasionally it made possible the diagnosis of this condition when the blood pressure was not impressively raised, such as $180 / 110 \mathrm{~mm}$. $\mathrm{Hg}$. Its value in the diagnosis of hypertension was emphasized in a patient who complained of headache and was found to have a blood 


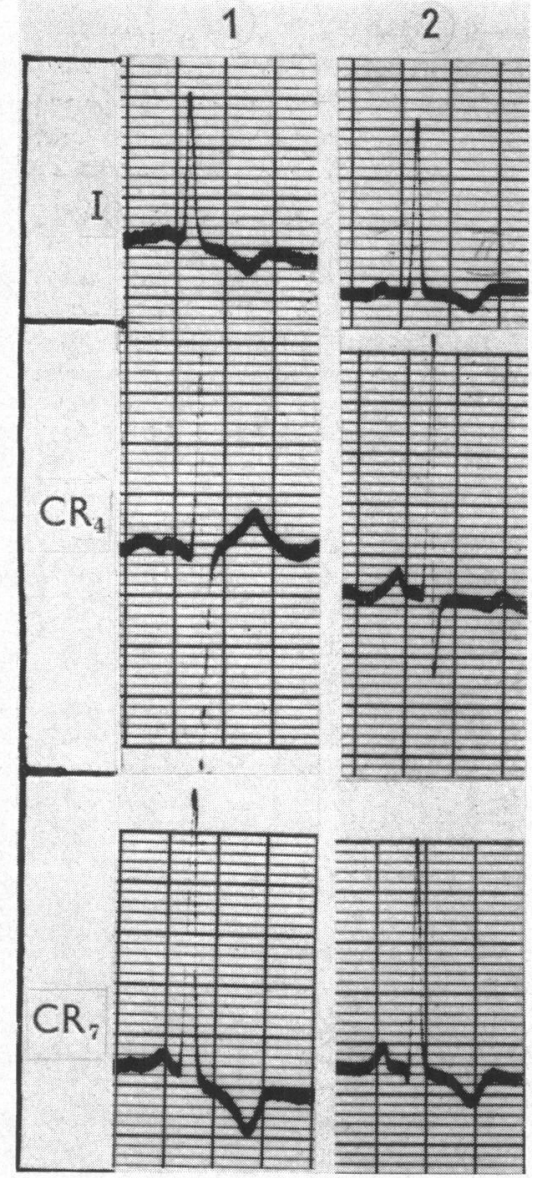

FIG. 4.-Characteristic S-T changes in leads I and CR7 and left ventricular excitation in two patients with uncomplicated systemic hypertension with blood pressure values of $240 / 140$ and $280 / 155 \mathrm{~mm}$. of $\mathrm{Hg}$ respectively.

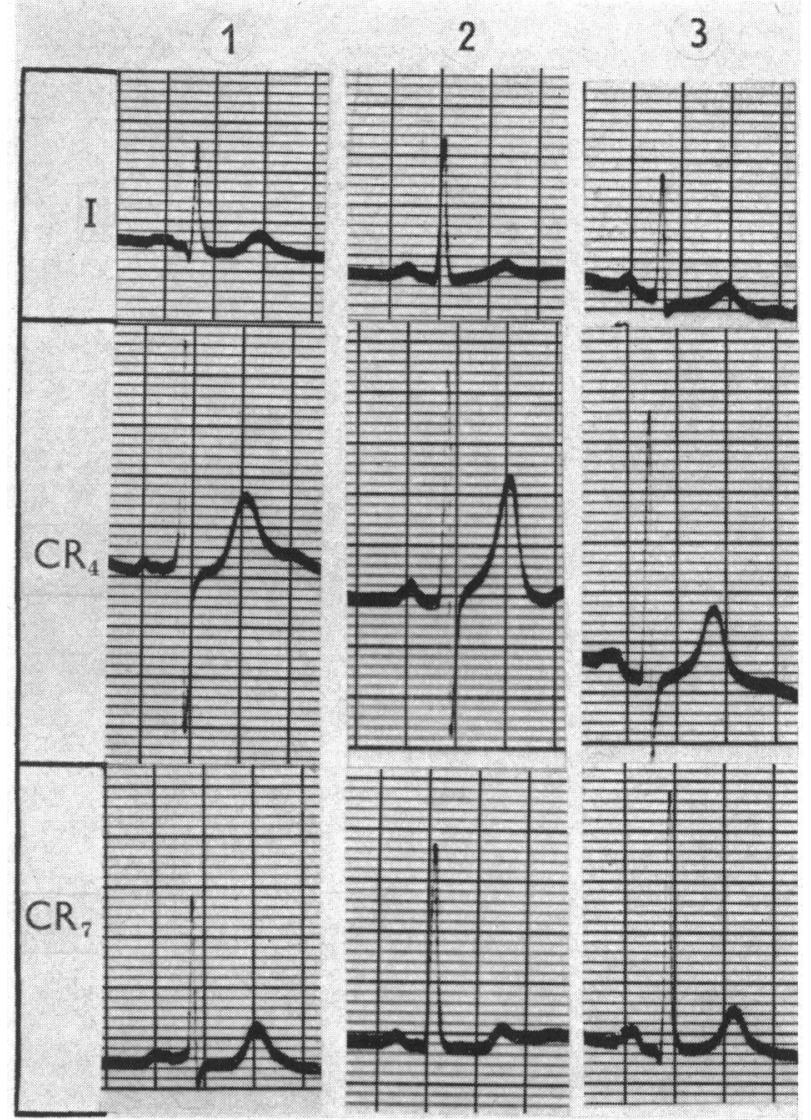

FIG. 5.-Early ST-T changes in leads I and/or CR7 in three patients with uncomplicated systemic hypertension with blood pressure values of $215 / 130,230 / 140$, and $230 / 110 \mathrm{~mm}$. of $\mathrm{Hg}$ respectively, and whose left ventricular excitation showed values for the lead-combination RI/RS4/R7 of 65, 70 , and $71 \mathrm{~mm}$. respectively. In Cases 1 and 2 the $T$ wave is low in lead I and there is plane S-T depression in lead CR7, but in Case 3, CR7 is normal and a low T in I is the only change.

pressure of 240/145 and papillœdema. In spite of minimal abnormalities in the retinal arterioles, a diagnosis of malignant hypertension was entertained at the start. The electrocardiogram, however, was normal, and showed neither left ventricular excitation, nor ST-T changes in leads I and CR7: on this premise the diagnosis of hypertension was rejected. When resting in bed the blood pressure ultimately subsided to $140 / 105$, and later the papillœdema disappeared following a successful removal of a cerebral tumour.

\section{COMPLICATED SYSTEMIC HYPERTENSION}

This group of 100 patients was made up of 79 men and 21 women, and their ages varied from 43 to 82 , the mean age being 62 years. All suffered from systemic hypertension to which cardiac infarction or heart failure had been added as a complication; 61 patients had cardiac 
1

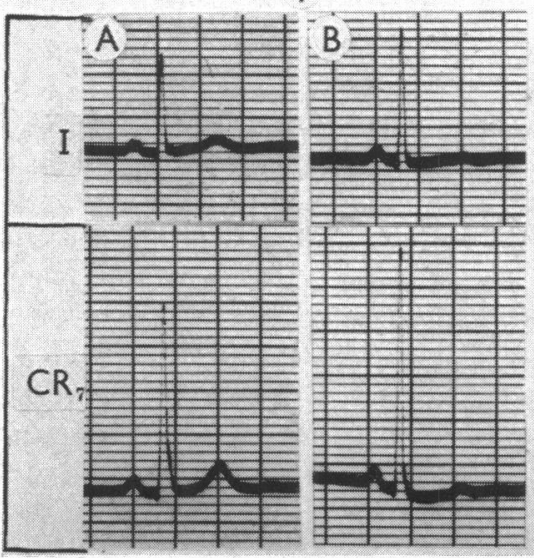

2

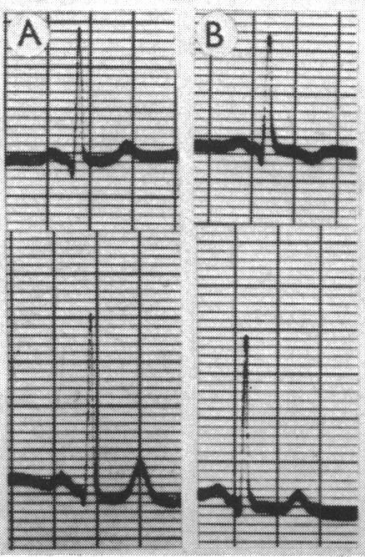

3

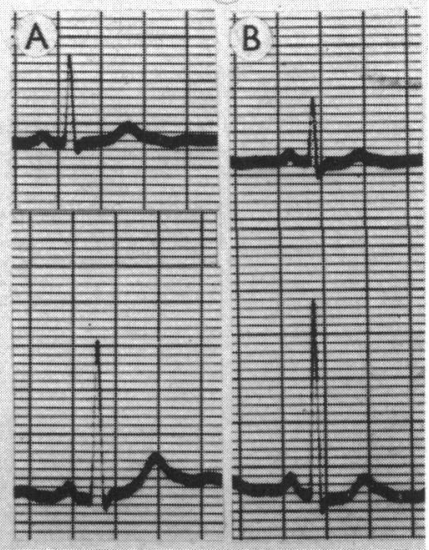

FIG. 6.-The progress of ST-T changes in leads I and CR7 in three patients with systemic hypertension. In Cases 1 and 3 there was an increase in left ventricular excitation, but not in Case 2. The interval between the tracings (A) and (B) was 7, 2, and 4 years respectively.

infarction without evidence of heart failure; and 39 had heart failure with breathlessness on exertion as a symptom and with pulmonary congestion showing at cardioscopy, while some of them had cardiac infarction as well.

The mean blood pressure was $215 / 125$ for the infarction group, and 215/135 for the failure group. Neither complication had depressed the blood pressure to any great extent, so that the diastolic pressure was less than $110 \mathrm{~mm}$. $\mathrm{Hg}$ in only 7 of the 61 patients with cardiac infarction, and in only 2 of the 39 with heart failure.

Allusion has already been made to the difficulty of telling in a patient with hypertension whether the ST-T changes in leads I and CR7 signify cardiac infarction situated laterally and posteroinferiorly, in addition to left ventricular hypertrophy. Should the patient complain of cardiac pain, the inference is natural that infarction has been added to the hypertension. Again, the electrocardiogram may show other signs of infarction, or may show differences in one tracing compared with another recorded previously, proving that infarction from coronary arterial disease has complicated the hypertension. Two more indices of this circumstance were tested, namely the extent of the changes in lead I compared with that in lead CR7 and the incidence of S-T depression in IIIR (lead III on deep inspiration) in the two clinical states.

In regard to the relative degree of ST-T depression in the two leads, the changes in CR7 were greater than those in I in 73 per cent of those patients with hypertension in whom no clinical or other proof existed that cardiac infarction had been added as a complication, while in the series where it was known on other grounds that the two conditions of hypertension and infarction were

TABLE V

ST-T Abnormalities in 100 Patients With Uncomplicated Systemic Hypertension, and in 61 in Whom CARDiaC INFARCTION HAD BEEN ADDED

\begin{tabular}{c|c|c|c|c|c|c}
\hline \multirow{2}{*}{ Clinical state } & \multicolumn{2}{|c|}{$\begin{array}{c}\text { Degree of S-T and T wave depression } \\
\text { in leads I and CR7 }\end{array}$} & \multicolumn{2}{|c}{ S-T depression in IIIR } \\
\cline { 3 - 8 } & & I>CR7 & Equal & CR7 > I & Present & Absent \\
\hline Uncomplicated hypertension. &.. & 8 & 19 & 73 & 29 & 71 \\
\hline Hypertension with added cardiac infarction & 26 & 18 & 56 & 70 & 30 \\
\hline
\end{tabular}




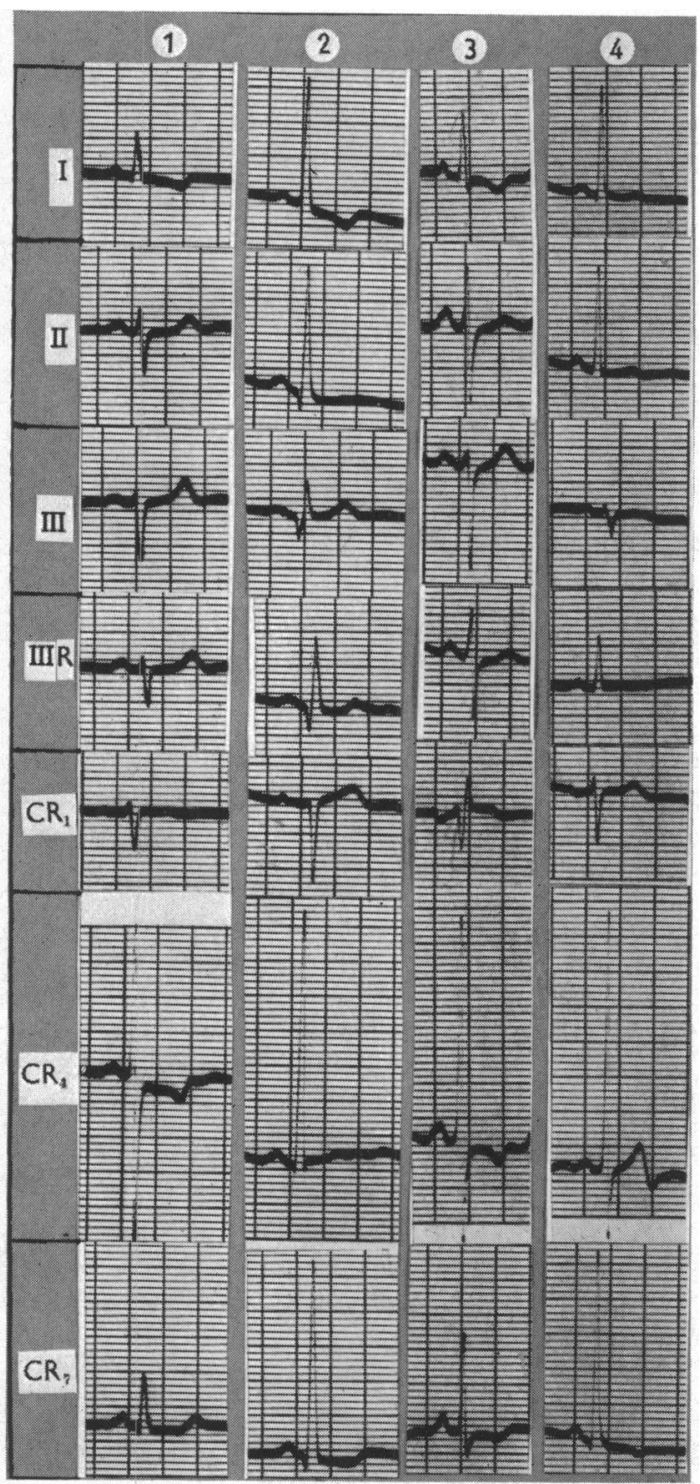

FIG. 7.-Four patients with systemic hypertension that has caused left ventricular excitation and ST-T changes in leads I and CR7. The addition of cardiac infarction in each is told by the following signs. Case 1: T wave more deformed in leads I and CR4 than in CR7 and a deep S wave in leads II, III, and IIIR. Case 2: $T$ wave in lead I more inverted than in CR7, significant $Q$ waves in II, III, IIIR, and CR1, and depression of S-T segment in IIIR. Case 3: T wave inversion greater in I and CR4 than in CR7, and depression of the $S-T$ in IIIR. Case 4: terminal dipping of the $T$ in CR4, and depression of the S-T segment in IIIR. present side by side, the incidence of preponderant $\stackrel{.}{.}$

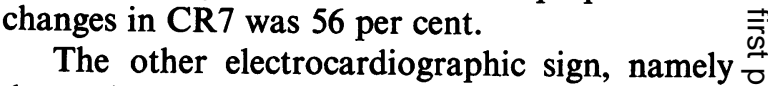
depression of the S-T segment in lead IIIR, was $\frac{\bar{\sigma}}{\mathrm{G}}$ also tested for its usefulness in telling whether cardiac infarction had been added to hypertension. $\stackrel{\Phi}{\triangle}$ This proved more helpful, for it was more than twice as frequent in patients in whom cardiac infarction had been added as a complication of hypertension than in those where the hypertension

was uncomplicated (Table $\mathrm{V}$ and Fig. 7).
Thus, although an unequivocal diagnosis of cardiac infarction involving the lateral and posteroinferior aspect of the left ventricle in the presence of hypertension is difficult, the conjoined lesion 8 can usually be determined from the presence of $ᄋ$ some of the following criteria - a history of cardiac $\overrightarrow{.}$ pain, electrocardiographic evidence of infarction in $\stackrel{\frac{5}{<}}{<}$ other places in the heart, changing of the cardiographic deformities over a short period of time, more obvious depression of the $\mathrm{S}-\mathrm{T}$ and $\mathrm{T}$ wave in lead I than in CR7, and a depression of the S-T segment in IIIR.

Although the electrocardiogram showed changes in the $T$ wave and $S-T$ segment in leads $I \stackrel{D}{\mathbb{D}}$ and CR7 in each patient, left ventricular excitation $\stackrel{\vec{P}}{\overrightarrow{7}}$ was absent in 36 of the 100 cases, namely in 19 웅 or 31 per cent of those with cardiac infarction and 17 or 44 per cent of those with heart failure. The mean amplitude in the combination RI/RS4/R7 was $59 \mathrm{~mm}$. for the $\stackrel{\infty}{\stackrel{\infty}{\circ}}$ infarction group and $53 \mathrm{~mm}$. for the failure group (Table I).

Lepeschkin (1951) stated that a decrease in the voltage of the electrocardiogram in the course of $₹$ dilatation of the heart was caused by an increase $\frac{}{3}$ in the intracardiac blood volume which acts as a $\rightarrow$ shunt for the cardiac conduction currents. Scott (1960) postulated that as heart failure commonly o accompanies left ventricular dilatation, œdema $N$ of the lungs also serves to short-circuit the flow of electrical current in the cardiac field, resulting in a decrease of voltage. A further possible cause 0 of diminished voltage in left ventricular dilatation might be the damage or destruction of muscle $\stackrel{0}{\rightarrow}$ fibres that may be present.

Some five conditions were examined in regard to their influence on depressing or annulling left ventricular excitation; these were a fall in the blood pressure, cardiac infarction, heart failure, cardiac enlargement, and the presence of an arrhythmia. 
The mean blood pressure in patients in the infarction group without left ventricular excitation was $215 / 125$ compared with $210 / 124$ in those where this sign was present, while the corresponding figures in the failure group were 200/130 and 225/140. As in the cases of uncomplicated hypertension, therefore, the height of the blood pressure in the present group did not appear to determine the presence or absence of left ventricular excitation.

Cardiac infarction had a definite depressant effect on left ventricular excitation. Thus, in the 100 cases of uncomplicated hypertension the left ventricular excitation was not once absent, while among the patients in whom cardiac infarction had been added this cardiographic sign was absent in 31 per cent.

In the group with heart failure, the absence of left ventricular excitation, present in only 44 per cent of the cases, seemed related in part to the severity of heart failure as judged by the degree of dyspnœa and the extent of pulmonary congestion when viewed by cardioscopy.

The degree of cardiac enlargement exerted a particular influence on the presence or absence of left ventricular excitation so that the heart showed either moderate or great enlargement in 83 per cent of the patients in whom there was no left ventricular excitation compared with 54 per cent among those who showed this cardiographic sign. Moreover, the proportion of instances exhibiting great cardiac enlargement was higher in the former class.

Left ventricular excitation was absent in nine patients with atrial fibrillation and present in 12 others, so that the arrhythmia by itself did not appear to reduce the incidence of this sign in patients with hypertension.

After consideration was given to the various circumstances that might reduce the increased amplitude of the left ventricular deflection expected in systemic hypertension, the two that appeared to exert greatest influence were the addition of substantial cardiac enlargement and cardiac infarction. In the case of the former, the reduced voltage is real, and not due to a shift leftwards of the transitional zone.

\section{SummaRY AND CONCLUSIONS}

The contribution that the electrocardiogram can make to the diagnosis of systemic hypertension has been examined.

A primary concern was the separation of patients with a raised blood pressure into rigidly defined groups. Thus, there were assembled for the investigation, 50 healthy young subjects and 470 other cases of 35 years of age or older: this second group consisted of 100 healthy subjects, 100 patients with cardiac infarction and a natural blood pressure, 70 subjects with hypertonia, 100 patients with uncomplicated systemic hypertension, and 100 patients in whom either cardiac infarction or heart failure had been added to hypertension.

The two main electrocardiographic deformities selected for examination were the amplitude of preponderant left ventricular deflections, and depression of the $S-T$ segment and $T$ wave in the limb lead $I$ and in the posterior axillary lead CR7. It was felt that lengthening of the intrinsic deflection did not materially contribute to the early diagnosis of left ventricular hypertrophy, and for that reason it was not specially examined.

Several leads, both separately and in combination, in which the electrical potential created by contraction of the left ventricle was preponderant were tested, and the deflections ultimately chosen were the $R$ wave in lead I (RI), the sum of the $R$ and S waves in the apical lead CR4 (RS4), and the $R$ wave in the left posterior axillary lead CR7 (R7). The amplitude of the $S$ wave in V1 or CR1 was found to be less reliable.

An amplitude of $55 \mathrm{~mm}$. was ultimately accepted as representing a standard measurement for the sum of the three selected ventricular deflections, RI/RS4/R7, which if equalled or exceeded was regarded as expressing an increased output effort, registered as a heightened electrical potential, and meaning a state of left ventricular excitation. In young subjects this value is some $10 \mathrm{~mm}$. higher, but in adults of 35 years of age or older, and it is with this age-group that the investigation was concerned, the standard value is $55 \mathrm{~mm}$. 
The incidence of such left ventricular excitation was then sought in the separate clinical groups. It was present in only 4 cases among the 100 healthy adults and in 9 among 100 patients with normal blood pressure but with cardiac infarction. In none of these 13 subjects did left ventricular hypertrophy develop when watched through several years.

Left ventricular excitation was absent in 70 subjects with hypertonia, in whom the blood pressure was always $200 / 110 \mathrm{~mm}$. or greater, and the mean pressure was $220 / 115 \mathrm{~mm}$. $\mathrm{Hg}$.

Left ventricular excitation was often absent in patients with systemic hypertension when cardiac infarction, cardiac failure, and especially considerable cardiac enlargement, had been added, although ST-T changes of left ventricular hypertrophy were present in all.

Left ventricular excitation was present in each of 100 patients with uncomplicated systemic hypertension. The sign was always accompanied by ST-T changes, and it never preceded these as evidence of left ventricular hypertrophy. It is in this role, however, that the electrocardiographic sign of left ventricular excitation assumes importance, in that its ready recognition should draw attention to the early ST-T changes that might otherwise escape notice. Moreover, the absence of the sign in a patient with a raised blood pressure excludes the diagnosis of systemic hypertension, unless in the presence of long-standing cardiac enlargement, especially if heart failure has been added.

\section{REFERENCES}

Barker, J. M. (1952). The Unipolar Electrocardiogram; a Clinical Interpretation. New York.

Bayley, R. H. (1958). Electrocardiographic Analysis. New York.

Bristow, J. D., Porter, G. A., and Griswold, H. E. (1961). Amer. Heart J., 62, 621.

Cabrera, E., and Monroy, J. R. (1952). Amer. Heart J., 43, 661 and 669.

, and Glaxiola, A. (1960). Amer. Heart J., 60, 296.

Evans, W. (1957). Lancet., 2, 53.

, and Hoyle, C. (1933). Lancet, 1, 1109.

Grant, R. P. (1953). Circulation, 7, 890.

(1957). Clinical Electrocardiography; the Spatial Approach. New York.

Grubschmidt, H. A., and Sokolow, M. (1957). Amer. Heart J., 54, 689.

Harrison, C. V., and Wood, P. (1949). Brit. Heart J., 11, 205.

Leatham, A. (1950). Brit. Heart J., 12, 213.

Leishman, A. W. D. (1951). Quar. J. Med., $20,1$.

Lepeschkin, E. (1951). Modern Electrocardiography. Baltimore.

Rykert, H. E., and Hepburn, J. (1935). Amer. Heart J., 10, 942.

Scott, R. C. (1960). Circulation, 21, 256.

Sedziwy, L., and Shillingford, J. (1961). Brit. Heart J., 23, 533.

Selzer, A., Ebnother, C. L., Packard, P., Stone, A. O., and Quinn, J. E. (1958). Circulation, $17,255$.

, Naruse, D. Y., York, E., and Kahn, K. A. (1958). Circulation, 18, 780.

Simpson, F. O. (1960). Brit. Heart J., 22, 227.

Sokolow, M., and Lyon, T. P. (1949). Amer. Heart J., 37, 161.

Stokes, W. (1946). Brit. Heart J., 8, 62.

Symons, C., and Wahl, E. (1961). Brit. Heart J., 23, 208.

Wilson, F. N., Johnston, F. D., Rosenbaum, F. F., Erlanger, H., Kossmann, C. E., Hecht, H., Cotrim, N., de Oliveira, R. M., Scarsi, R., and Barker, P. S. (1944). Amer. Heart J., 27, 19.

Winsor, T., and Beckner, G. (1955). California Med., 82, 151.

Ziegler, R. F. (1951). Electrocardiographic Studies in Normal Infants and Children. Springfield. 